\title{
MEDICINE ON THE TERRACES
}

\author{
Andrew Whitton, TD, MRCGP
}

Andrew Whitton is a Lancaster general practitioner (GP) with a passion for Bolton Wanderers Football Club. He has previously written for the Journal of his experiences with the Territorial Army Medical Services. Here he describes another of the varied extracurricular activities in which GPs can become involved. He has worked as a 'crowd doctor' at the Reebok Stadium since 1999.

Following the publication of the Taylor Report in 1990, the Football League's Honorary Consultant Medical Advisor made a number of recommendations. One of these was the legal requirement to provide medical cover at sporting events. A number of doctors already provide medical cover at an increasing variety of sporting events such as air shows and music festivals.

\section{ROLE OF THE CROWD DOCTOR}

The crowd doctor has a number of roles:

- to provide Immediate Medical Care to members of the public within the stadium and its immediate environs

- to act as the 'Silver' Medical Officer in the event of a major disaster

- to liaise with the Greater Manchester Ambulance Service (GMAS)

- to provide expert medical advice to the ground safety officer

- to support the volunteers of the St John's Ambulance service

The crowd doctor is supported in his role by additional medical resources, for which each home game should include:

- two crowd doctors

- eight GMAS paramedics

- twelve St John's Ambulance personnel (varying levels of medical expertise)

In addition there are stewards and police whose responsibilities are mainly crowd control and public order (rather than first aid).

\begin{tabular}{|l|}
\hline Medical Officers involved with a major disaster \\
\hline Gold Medical Officer $\begin{array}{r}\text { - the officer in charge of the gold area, } \\
\text { ie at the main controlling } \mathrm{HQ}, \\
\text { eg the regional } \mathrm{HQ}\end{array}$ \\
\hline Silver Medical Officer $\begin{array}{r}\text { - the officer in charge of the silver area, } \\
\text { ie the immediate incident }\end{array}$ \\
\hline $\begin{array}{r}\text { Bronze Medical Officer - the officer in charge of the bronze area, } \\
\text { ie with the casualties }\end{array}$ \\
\hline
\end{tabular}

\section{FACILITIES}

The Reebok Stadium is a very modern facility having two First Aid rooms, located at opposite corners of the ground. These are modestly equipped - one has five bays, the other two. The football club provides a minimum level of equipment but the more technical and resuscitation apparatus, including emergency drugs, are provided by GMAS and the St John's Ambulance.

In addition, GMAS always has two emergency vehicles on site, one of which is a Major Incident Support Vehicle.

\section{LEGISLATION}

The position of crowd doctor was necessitated following publication of Lord Justice Taylor's report on the Hillsborough Disaster of 1989. This stated clear guidelines for the requirement of medical support at sporting events, and was subsequently adopted by the Football League.

The required staffing levels are based on a calculation of medical risk. The guidelines are set at one first aider per 1000 spectators, and if the crowd is expected to exceed 2000 a doctor must be in attendance.

\section{CLINICAL GOVERNANCE}

The Football Association's Medical Education Department, in conjunction with the British Association for Immediate Medical Care and the Royal College of Surgeons (Edinburgh Faculty for Pre-Hospital Care), organises crowd doctor courses. It is recommended that newly recruited crowd doctors undertake the Diploma in Immediate Care from the Royal College of Surgeons of Edinburgh. For crowd doctors in post before 2001 these requirements do not apply. It is mandatory, however, for these doctors to attend a refresher course and skills update course every three years. This course is run by the Football Association at Lilleshall.

The British Medical Association (BMA) recommends that doctors at sporting events need knowledge of resuscitation procedures, airway maintenance, fracture immobilisation and the treatment of anaphylaxis. Advanced Life Support, Advanced Trauma Life Support and Paediatric Life Support courses would all be appropriate.

Bolton Wanderers FC has accepted this responsibility and generously funds the courses. Additionally, they have encouraged their crowd doctors to attend a Major Incident Medical Management System (MIMMS) course. This course is very relevant to the type of mass casualty incident that may occur at such an event.

\section{WHY DO IT?}

Participating in event medicine is exciting. I have the 
opportunity to be an integral part of a football club as well as being a fan. There are spin-offs such as providing medical cover when the stadium is used for other activities. Personally, I have supported Elton John \& Oasis in concert, watched Rugby League test matches and enjoyed the Commonwealth Games.

The provision of pre-hospital care is an interesting addition to mainstream general practice. It helps to maintain clinical skills.

For sporting fans it can also be an ideal opportunity to get closer to the action and actually participate rather than merely observe.

\section{FURTHER READING}

Dignon and Hearns. Event Medicine 323(7326):S2-7326. BMJ Career Focus

Health and Safety Executive. The event safety guide. London; 1999

Doctor's assistance to sports clubs and sporting events. British Medical Association. www.bma.org.uk

The Hillsborough Stadium Disaster: 15 April 1989. Inquiry by Lord Justice Taylor: Final Report. London: HMSO; 1997

\section{THE VIRTUAL CONSULTATION}

\section{Marwan Bukhari; Rakshi Memon; John Halsey}

The Rheumatology Department at the Royal Lancaster Infirmary has won the $\mathbf{2 0 0 5}$ Wyeth Innovations Award, which was awarded for the innovation of email communication and support between the general practitioners (GPs) and the consultant rheumatologists.

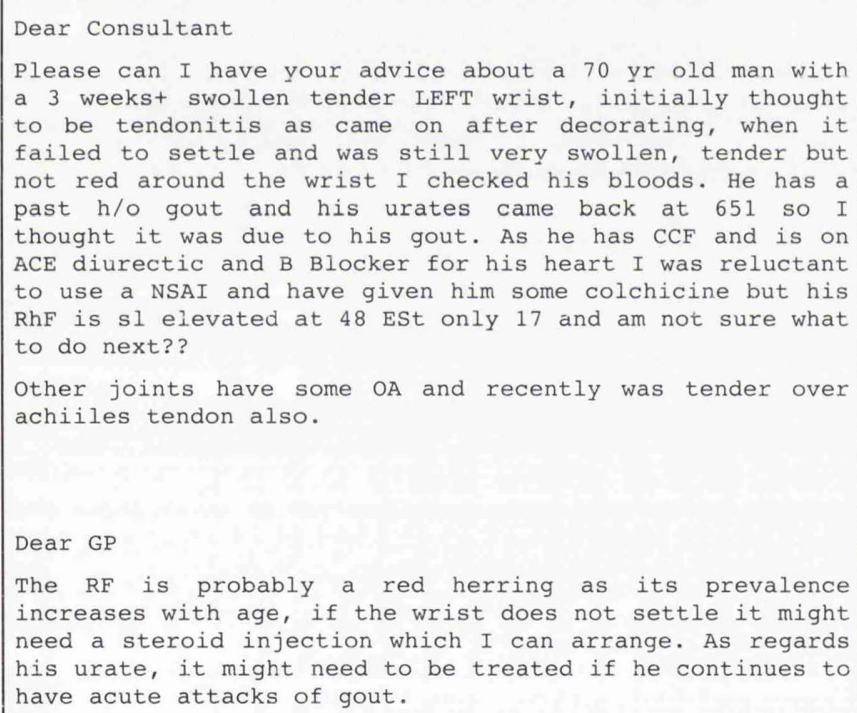

There is an impression that not all referrals to rheumatology clinics require an outpatient appointment as some cases could be managed in primary care with appropriate advice and guidance. As a pilot site for the Action on Orthopaedics Programme, which is part of the NHS Modernisation Agency, we have developed an email advice service for GPs in Morecambe Bay (population 312,000).

\section{METHODS}

In collaboration with the Primary Care Trust (PCT), Morecambe Bay Hospitals Trust and information technology department a secure email advice clinic was established and a pilot clinic commenced in November 2001. Email enquiries from GPs are dealt with in a weekly clinic by a consultant rheumatologist $(\mathrm{MB})$. A survey of the first 84 referrals was made.

\section{RESULTS}

Fifty-three $(63 \%)$ of the referrals were dealt with in primary care following advice and guidance and only $31(37 \%)$ needed referral to secondary care. Of these, $21(68 \%)$ were seen in the Rheumatology Department and ten $(32 \%)$ in the Orthopaedic or Neurology Departments. The time needed to answer emails was considerably less than the time it would have taken to see these patients in secondary care. Additionally, the consultant advice was received quicker than it would have been done by traditional means. Very positive feedback has been received from GPs about the collaborative innovation with a request that a similar service be provided by other specialties.

The consultant answers emails on a daily basis, with queries ranging from specific questions about patients not seen yet and in whom the management is doubtful to established patients who have developed new problems. It allows a pro-active, fast and efficient method of communication. Additionally, there is an element of education as patients are managed interactively and results are requested and reviewed jointly between primary and secondary care.

This has garnered a lot of support and indeed there has been a request from the PCT that an email advice service for GPs should be expanded throughout the other specialities. Within the Rheumatology Department the service has also been extended to include community physiotherapists. The department was chosen from a shortlist of five hospital trusts by the awards committee on Tuesday, 19th April, 2005. The judging panel included professors of rheumatology, specialist nurses and patient representatives.

\section{CONCLUSIONS}

This survey has confirmed that an electronic advice service is a valuable means of improving the management of musculoskeletal diseases in primary care with the potential to reduce referrals for outpatient appointments.

An audit of this service has previously been presented as a poster at the British Society for Rheumatology meeting in 2003. (Rheumatology 2003:42(Supp 1);69) 